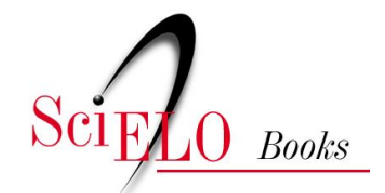

\title{
A industrialização da agricultura na usina Nova América
}

\author{
Jozimar Paes de Almeida
}

ALMEIDA, JP. A industrialização da agricultura na usina Nova América. In: A extinção do arco-íris: ecologia e história [online]. Rio de Janeiro: Centro Edelstein de Pesquisa Social, 2008, pp. 35-56. ISBN 978-85-99662-69-4. Available from SciELO Books <http://books.scielo.org $>$.

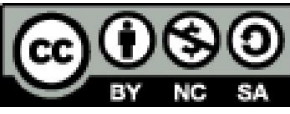

All the contents of this chapter, except where otherwise noted, is licensed under a Creative Commons Attribution-Non Commercial-ShareAlike 3.0 Unported.

Todo o conteúdo deste capítulo, exceto quando houver ressalva, é publicado sob a licença Creative Commons Atribuição Uso Não Comercial - Partilha nos Mesmos Termos 3.0 Não adaptada.

Todo el contenido de este capítulo, excepto donde se indique lo contrario, está bajo licencia de la licencia Creative Commons Reconocimento-NoComercial-CompartirIgual 3.0 Unported. 


\section{A industrialização da agricultura na Usina Nova América}

A indústria deverá preocupar-se cada vez mais em proteger pelo menos em parte o meio ambiente, e isso não por inquietação filantrópica da famosa e sinistra 'qualidade de vida', mas simplesmente para poder continuar a funcionar.

Jean Pierre Dupuy

Várias são as concepções sobre a grande propriedade. Ressalto aqui a de Marx, porque a considero mais próxima da análise que desenvolvo neste trabalho:

Grande indústria e grande agricultura, exploradas industrialmente, atuam conjuntamente. Se, originalmente, elas se diferenciam pelo fato de que a primeira devasta e arruína mais a força natural da terra, mais tarde, ao longo do desenvolvimento, ambas se dão as mãos, ao passo que o sistema industrial na zona rural também extenua os trabalhadores e, por sua vez a indústria e o comércio proporcionam à agricultura os meios para esgotamento da terra ${ }^{31}$.

As frases sublinhadas, nesta última citação, esclarecem às relações existentes entre indústria e agricultura nas suas atividades de degradação das forças naturais: humana e telúrica (ecossistema).

Esta destruição se amplia quando estes meios de produção se fundem na agroindústria provocando alterações fundamentais na utilização intensiva das forças naturais, pela velocidade imposta à produção com objetivos de lucro visando a venda do produto no mercado.

A grande empresa rural U.N.A., instalada na região de Assis, será orientada por uma racionalidade capitalista empresarial de produção para o mercado, assim como também se constituirá num mercado consumidor das indústrias que produzem para a agricultura (inseticidas, maquinários, adubos, implementos, etc.).

A utilização deste conjunto tecnológico de implementos, pela empresa em estudo e outras empresas similares, atrairá para a Cidade uma fábrica de adubos e defensivos agrícolas, a Ultrafértil, que ao comemorar a sua instalação, expressa no jornal de maior circulação da cidade as suas concepções de desenvolvimento.

O desenvolvimento econômico de uma região se caracteriza pelo aumento de produção, pelo aumento dos bens de produção e pelo aumento de renda 'per capita', possibilitando maior poder aquisitivo.

A renda "per capita", como se sabe, é resultado de um cálculo matemático que não leva em conta a sua distribuição e a propriedade dos meios de produção. Seu cálculo é realizado pela somatória da renda de todas as pessoas consideradas produtoras, sendo dividida por este mesmo número total de pessoas; desta forma não revela a concentração de renda, devido à divisão harmônica entre os produtores da somatória da renda.

Sem se contar que este aumento de produção caracterizado como "desenvolvimento"

31. MARX, Karl. O Capital. Trad. Regis Barbosa e Flávio R. Kothe, 2. a ed.., São Paulo, Nova Cultural, 1985, Livro 3, Vol. 5, Tomo 2, p. 266. 
econômico, descapitaliza e destrói a fonte de todos os recursos, a natureza. Desta forma ao considerar a economia como uma disciplina da ecologia, não existe lucro, mas sim prejuízo no cálculo da descapitalização extenuante da natureza.

Como se sabe, o "desenvolvimento" de um país é calculado pelo índice do Produto Nacional Bruto. Este registra o movimento de materiais (mercadoria) impulsionado pelo capital. Neste cálculo, porém, não se desconta o esgotamento do solo, ar, água, em suma, da qualidade da vida.

Até mesmo no caso de doença e morte do ser humano, tal fato é entendido como um "desenvolvimento" do país pelo aumento do P.N.B. em consumo: hospitais, remédios, médicos, energia, funerárias e sepulturas, na lápide dos mortos se poderia até constar, ironicamente, uma homenagem sincera das empresas do país: "Muito obrigado senhor X, por nos ter dado lucro até na morte."

Nos anos de 1974/75, a agroindústria sucro-alcooleira viu-se favorecida devido a problemas de conjuntura internacional. O mercado mundial não conseguiu realizar um acordo internacional para o açúcar, que estabelecesse o preço e as quotas de produção de cada país fornecedor, havendo também quedas de produção em vários outros países produtores.

O petróleo, largamente utilizado na indústria e nos transportes, em que está alicerçada a maior parte da malha viária brasileira, sofreu acréscimos consideráveis de preços por parte de seus fornecedores (Organização dos Países Exportadores de Petróleo). Como o Brasil importava a quase totalidade desta matéria prima, aumentaram os grandes déficits na balança comercial. A tentativa de saída governamental foi o projeto do álcool, vindo a beneficiar os seus produtores. Questão a ser estudada é se essa empreitada não estava na estratégia dos países dominantes do sistema capitalista.

O apoio governamental através do projeto facilitou a hegemonia da cana-de-açúcar como uma das principais culturas da região, sendo noticiada assim pelo jornal da cidade "Voz da terra":

A Usina Nova América S.A recebeu recentemente resposta da carta consulta que havia remetido ao conselho nacional do álcool, requerendo aumento da quota de moagem por dia. Isso exigirá, segundo cálculos técnicos cerca de 3.500 alqueires de terra cultivados de cana, constituindo-se tal evento numa nova opção de plantio para os agricultores cujas propriedades circundam num raio de 25 quilômetros do complexo industrial da empresa.

A possibilidade de produtores agrícolas que operam em várias culturas como soja, trigo, café, etc., com mais de 70 alqueires cultivados, transformarem suas propriedades em canaviais desponta com naturalidade, já que a mudança requer mínimas alterações em termos de maquinários, e ainda porque tais operações são totalmente financiáveis pelo Banco do Brasil em faixa própria através do Pró-álcool.

Para se ter uma visualização da produção agroindustrial da U.N.A., desde 1947 até 1984, foram confeccionados quatro gráficos com o objetivo de comparação dos dados fornecidos pela U.N.A., acompanhados por duas tabelas.

Tomo como referência neste gráfico - comparação visual - o privilégio por períodos produtivos, objetivando destacar o crescimento da Usina vinculada necessariamente a fatores do mercado sucro-alcooleiro que incentivaram este crescimento. O programa governamental do álcool tem um destaque principal enquanto alternativa energética escolhida pelo governo para enfrentar a crise mundial do petróleo, intensamente utilizado nas indústrias e nos transportes.

Isto pode ser constatado no Gráfico 1 - produção de álcool em litros de 1954 a 1984, demonstrando um crescimento acelerado da produção a partir de 1976 com nítida influência dos incentivos do Pró-álcool. 
Até 1976 a produção de álcool não é privilegiada, realizando-se de uma forma oscilante em comparação com o açúcar - gráfico 2 - em que se constata uma estabilidade crescente progressiva. Quando existe uma queda na produção do açúcar, esta relaciona-se a problemas naturais, "carvão da cana", ou diminuição da área de plantio num ano - 1975 (vide gráfico 3 - Área de cana plantada em (Ha) de 1947 a 1984), em que se configura uma crise de conjuntura internacional ou mesmo ao se realizar um rápido incremento na produção do álcool em 1970 e 1979, por ser o açúcar uma matéria prima para a produção do combustível.

Estas oscilações são significativas no sentido de mostrar os privilégios que ocorrem na agroindústria, influência em sua maior parte de fatores conjunturais, mas, não se deve esquecer também que a produção na agricultura é sazonal. 
TABELA 1

Aspecto comparativo da quantidade de açúcar (saco de $50 \mathrm{Kg}$ ) e álcool (por litro) por área (Hectare) de cana cultivada 1947-1984

Usina Nova América

\begin{tabular}{|c|c|c|c|}
\hline Ano & $\begin{array}{c}\text { Área } \\
\text { (em ha) }\end{array}$ & $\begin{array}{l}\text { Qtd. açúcar } \\
\text { (saco } 50 \mathrm{Kg} \text { ) }\end{array}$ & $\begin{array}{l}\text { Qtd. álcool } \\
\text { (litro) }\end{array}$ \\
\hline 1947 & 274 & 22.600 & \\
\hline 1948 & 317 & 26.822 & 0 \\
\hline 1949 & 122 & 10.082 & 0 \\
\hline 1950 & 266 & 30.160 & 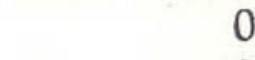 \\
\hline 1951 & 408 & 42.679 & 0 \\
\hline 1952 & 507 & 49.207 & 0 \\
\hline 1953 & 388 & 38.196 & 0 \\
\hline 1954 & 566 & 69.992 & 125.083 \\
\hline 1955 & 565 & 65.142 & 687.000 \\
\hline 1956 & 808 & 96.375 & 703.000 \\
\hline 1957 & 964 & 100.020 & 1.793 .000 \\
\hline 1958 & 1.080 & 137.200 & 1.113 .000 \\
\hline 1959 & 1.373 & 149.605 & 1.370 .000 \\
\hline 1960 & 1.555 & 183.639 & 1.956 .400 \\
\hline 1961 & 1.547 & 185.250 & 1.900 .530 \\
\hline 1962 & 1.636 & 200.285 & 1.474 .010 \\
\hline 1963 & 1.878 & 182.211 & 2.287 .030 \\
\hline 1964 & 2.260 & 282.125 & 2.528 .033 \\
\hline 1965 & 3.107 & 386.127 & z.521.199 \\
\hline 1966 & 2.903 & 244.158 & 6.361 .064 \\
\hline 1967 & 2.724 & 304.426 & 4.102 .646 \\
\hline 1968 & 3.221 & 474.538 & 4.369 .147 \\
\hline 1969 & 3.192 & 409.952 & 3.725 .150 \\
\hline 1970 & 3.523 & 315.738 & 7.042 .155 \\
\hline 1971 & 4.769 & 535.296 & 7.070 .000 \\
\hline 1972 & 4.290 & 536.768 & 5.441 .100 \\
\hline 1973 & 4.604 & 603.402 & 3.837 .300 \\
\hline 1974 & 4.831 & 613.957 & 4.028 .040 \\
\hline 1975 & 3.645 & 398.419 & 3.862 .090 \\
\hline 1976 & 5.599 & 654.110 & 5.725 .075 \\
\hline 1977 & 7.494 & 740.000 & 12.702 .630 \\
\hline 1978 & 7.692 & 591.000 & 15.624 .665 \\
\hline 1979 & 10.550 & 519.600 & 34.700 .640 \\
\hline 1980 & 15.042 & 935.883 & 49.300 .000 \\
\hline 1981 & 16.560 & 1.312 .444 & 48.410 .000 \\
\hline 1982 & 18.361 & 1.400 .270 & 52.200 .000 \\
\hline 1983 & 27.087 & 1.347 .200 & 104.460 .000 \\
\hline 1984 & 25.137 & 1.156 .481 & 107.500 .000 \\
\hline
\end{tabular}


No entanto, se utilizar a tabela 2 - de moagem de cana por tonelada - cana de 1947 - 1984 e, o seu gráfico 4, que leva o mesmo nome, assim também o gráfico 3, já citado, como básicos, podese perceber que as oscilações existentes no decréscimo da produção são secundárias no processo global de produção da U.N.A., sendo explicáveis por fatores naturais ou, de conjuntura internacional e nacional.

O aumento da produção na agricultura pode ser realizado de várias formas. A primeira delas diz respeito à ampliação do espaço plantado, considerando-se que a área acrescida seja provida de terras no mínimo de igual fertilidade. $\mathrm{O}$ aumento na produção é proporcional à quantidade de novas terras integradas.

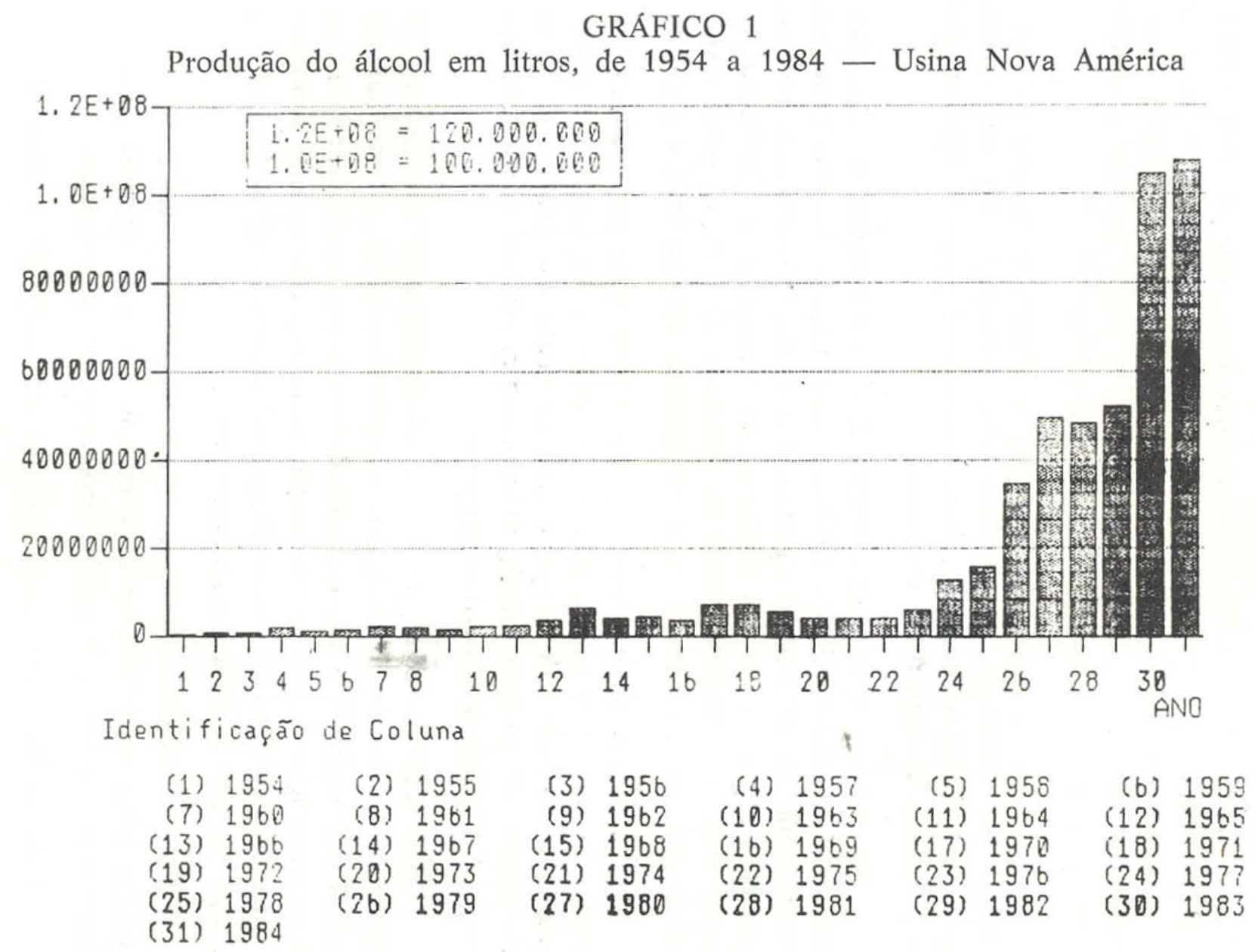

Uma segunda forma poderia ser alcançada com um aumento no potencial de produtividade ligado, em primeiro lugar, à fertilidade do solo e, em segundo, a um aumento de velocidade no ciclo germinativo e de maturação da planta (revolução genética), objetivando aumentar a quantidade de matéria bruta (vegetais) dentro do mesmo espaço de tempo em que se produzia naturalmente.

Preliminarmente com essas considerações é possível compor um quadro sobre as condições de produção em uma empresa agrícola, objetivando compará-la com a produção em uma fábrica.

Para realizar uma ampliação de sua produção é necessária a ocorrência de alguns dos seguintes fatores: aumento do tempo de produção (jornada de trabalho), da velocidade de produção (ritmo imposto pela máquina), da quantidade e qualidade das máquinas (e por decorrência, da energia e operários para o seu funcionamento), como também da quantidade e qualidade da matéria bruta a ser transformada em produto. As modificações tecnológicas aplicadas neste processo têm 
importância fundamental e são frutos da ciência.

Este conjunto emaranhado de fatores do sistema capitalista de produção assemelha-se a uma floresta em funcionamento sem, entretanto o seu mecanismo principal, o equilíbrio homeostático, ocasionando a ausência de reciclagem dos recursos naturais limitados e simplificação do ecossistema da vida, pelo privilégio do lucro provocando o ciclo da morte do capital por destruir a vida.

GRÁFICO 2

Produção de Açúcar em sacos de 50 Kg., de 1947 a 1984 - Usina Nova América

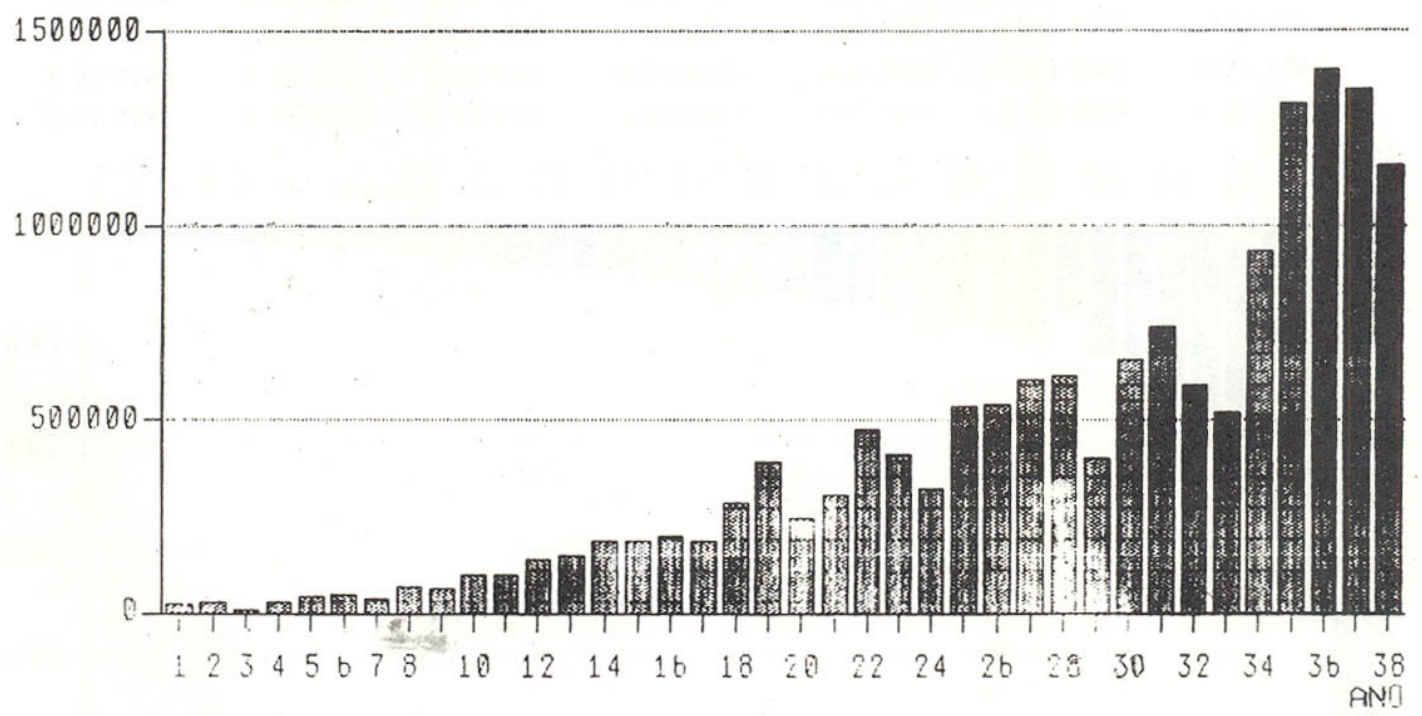

$\begin{array}{lllllll}\text { (1) } 1947 & \text { ( 2) } 1948 & \text { (3) } 1949 & \text { (4) } 1950 & \text { (5) } 1951 & \text { (6) } 1952 & (7) 1953 \\ \text { ( 8) } 1954 & \text { (9) } 1955 & \text { (10) } 1956 & \text { (11) } 1957 & \text { (12) } 1958 & \text { (13) } 1959 & (14) 1960 \\ \text { (15) } 1961 & \text { (16) } 1962 & \text { (17) } 1963 & \text { (18) } 1964 & \text { (19) } 1965 & \text { (20) } 1966 & (21) 1967 \\ \text { (22) } 1968 & \text { (23) } 1969 & \text { (24) } 1970 & \text { (25) } 1971 & \text { (26) } 1972 & (27) 1973 & (28) 1974 \\ \text { (29) } 1975 & \text { (30) } 1976 & \text { (31) } 1977 & \text { (32) } 1978 & \text { (33) } 1979 & \text { (34) } 1980 & (35) 1981 \\ \text { (36) } 1982 & \text { (37) } 1983 & \text { (38) } 1984 & & & & \end{array}$


GRÁFICO 3

Área de cana plantada em (Ha) de 1947 a 1984 - Usina Nova América

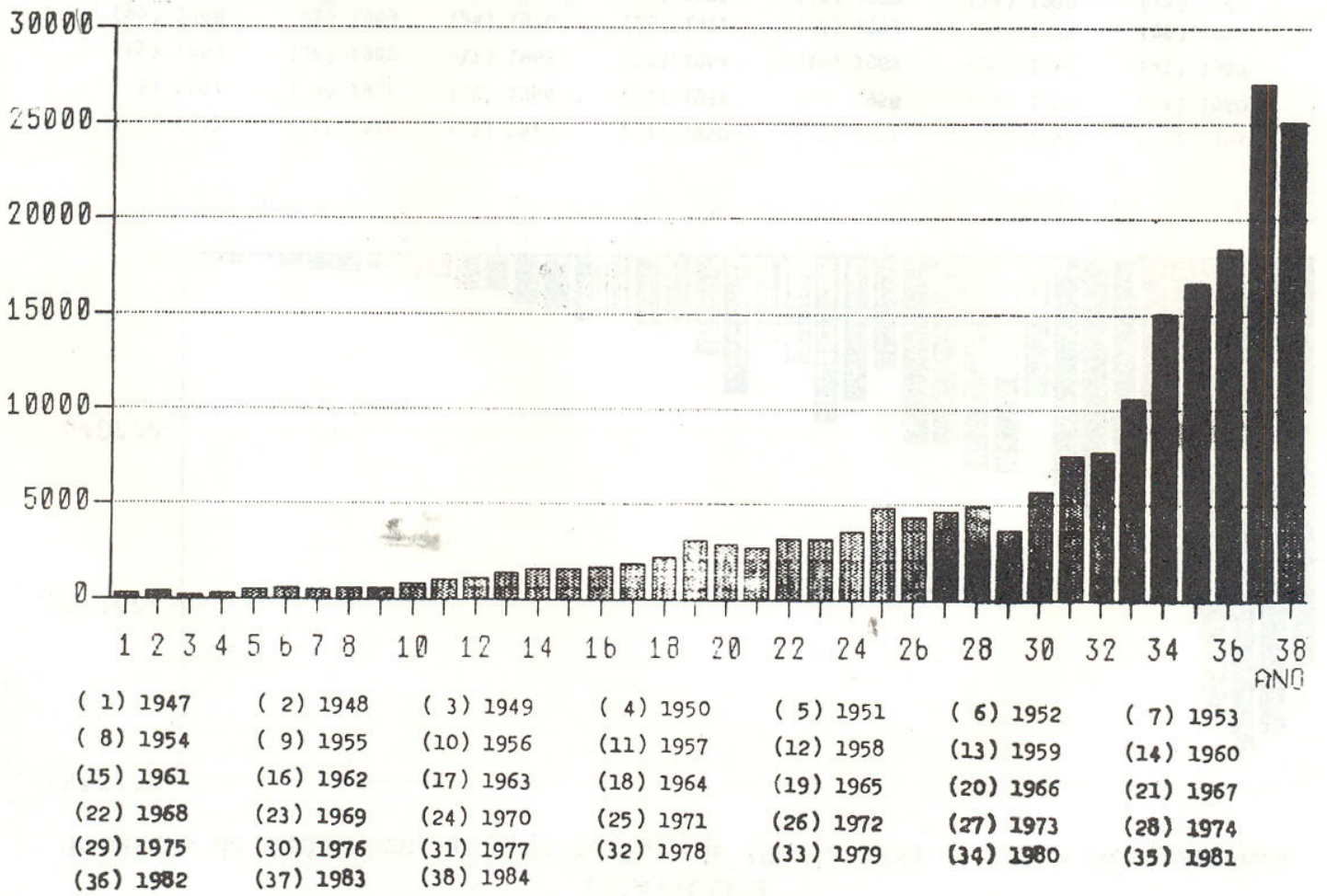

GRÁFICO 4

Moagem da cana por tonelada-cana de 1947 a 1984

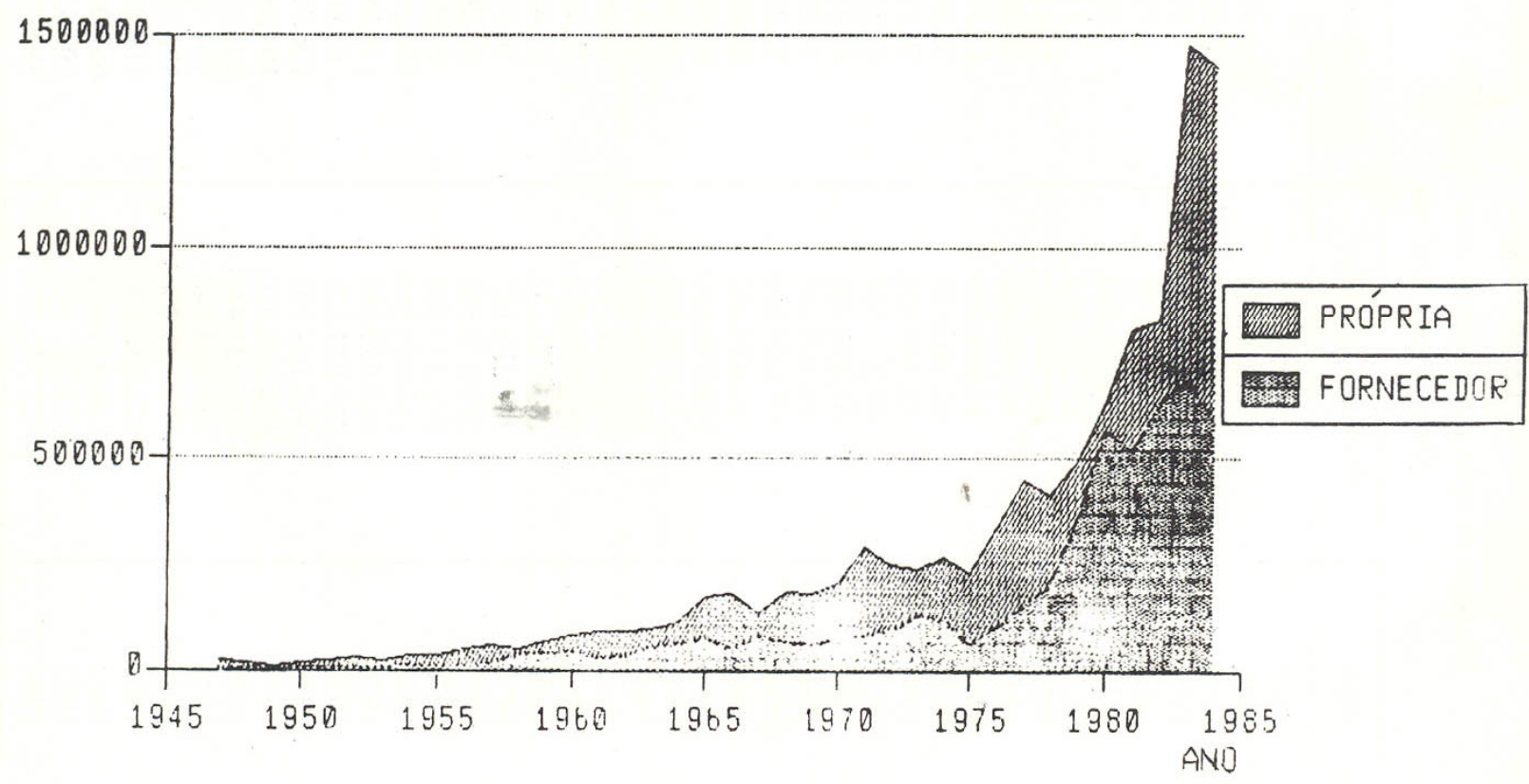


A opção do plantio da cana vem em resposta a um mercado de comercialização e consumo. Quando este mercado se toma favorável, aumenta-se a demanda pelo produto abrindo opções ao produtor; neste caso, o usineiro intensifica a sua produção.

O empresário agrícola instalado no país ligado ao setor da agroindústria sucro-alcooleira, viu-se favorecido pelo programa governamental do Pró-álcool (decreto 79.593 de 1975), que lhe dava subsídios sob forma de créditos pelas instituições financeiras governamentais (Banco Central e do Brasil), no sentido de ampliar a sua produção com preços garantidos de compra de seu produto.

Era a opção energética do álcool como substituto do petróleo assumido pelo Estado. O apoio financeiro estrutural foi dado às grandes destilarias, privilegiando claramente os detentores do grande capital, concentrando as usinas e o poder nas mãos de poucos.

Ao se comparar o atendimento do governo dado aos usineiros, com os produtores agrícolas de gêneros alimentícios que em sua quase totalidade compõem-se de pequenos proprietários, vê-se claramente o privilégio dado aos primeiros.

Esta relação direta realizada entre os representantes do Estado e a classe detentora dos grandes meios de produção, é bastante ilustrativa do tratamento especial a eles dispensado. $\mathrm{O}$ Estado intervém como elemento dinamizador, regulador e direcionador da economia. Isto não exclui necessariamente o laissez-faire do mercado. No entanto, a opção energética do Pró-álcool veio favorecer as grandes empresas rurais e as automobilísticas, em sua estrutura de produção, portanto, de poder.

Definem-se, em conseqüência, suas relações sociais de produção e as formas dessas relações com o meio ambiente, com seus valores de apropriação privada, o chamado "progresso e desenvolvimento", segundo declarações, de um usineiro na imprensa: "Cremos na terra, que com suas riquezas naturais, se constitui na mola propulsora do progresso da nossa nação." Está claro para o usineiro que o conceito de progresso se realiza com a exploração das 'riquezas naturais que em nosso sistema econômico são mercadorias. 


\section{TABELA 2}

Moagem de cana por tonelada-cana de 1947 a 1984 Usina Nova América

\begin{tabular}{|c|c|c|c|}
\hline Ano & & Produção própria & Produção fornecedor \\
\hline 1947 & & 21.901 .000 & 0.000 \\
\hline 1948 & & 16.914 .419 & 8.471 .236 \\
\hline 1949 & & 7.941 .870 & 1.804 .530 \\
\hline 1950 & & 15.635 .490 & 5.615 .030 \\
\hline 1951 & & 23.819 .140 & 8.795 .790 \\
\hline 1952 & & 31.121 .460 & 9.405 .930 \\
\hline 1953 & & 23.357 .443 & 7.713 .837 \\
\hline 1954 & & 36.480 .890 & 10.421 .790 \\
\hline 1955 & & 35.132 .280 & 10.031 .170 \\
\hline 1956 & 4 & 51.889 .020 & 12.778 .340 \\
\hline 1957 & & 60.196 .650 & 16.884 .140 \\
\hline 1958 & & 48.199 .407 & 38.237 .529 \\
\hline 1959 & & 68.520 .707 & 41.332 .265 \\
\hline 1960 & & 81.456 .980 & 42.934 .740 \\
\hline 1961 & & 90.518 .410 & 33.271 .650 \\
\hline 1962 & & 93.609 .010 & 37.296 .380 \\
\hline 1963 & & 97.424 .030 & 52.810 .680 \\
\hline 1964 & & 116.986 .810 & 63.801 .006 \\
\hline 1965 & & 171.619 .548 & 76.905 .167 \\
\hline 1966 & & 180.820 .665 & 51.449 .631 \\
\hline 1967 & & 135.894 .157 & 81.951 .813 \\
\hline 1968 & 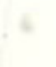 & 187.200 .213 & 70.467 .768 \\
\hline 1969 & & 183.892 .856 & 61.458 .421 \\
\hline 1970 & & 205.186 .877 & 76.623 .655 \\
\hline 1971 & & 291.278 .626 & 82.265 .834 \\
\hline 1972 & & 248.242 .093 & 94.993 .381 \\
\hline 1973 & & 237.025 .555 & 131.297 .237 \\
\hline 1974 & & 266.580 .945 & 119.884 .265 \\
\hline 1975 & & 229.833 .101 & 61.801 .523 \\
\hline 1976 & & 341.164 .195 & 106.790 .357 \\
\hline 1977 & & 444.869 .810 & 154.660 .971 \\
\hline 1978 & & 414.224 .942 & 201.156 .176 \\
\hline 1979 & & 489.425 .890 & 354.567 .764 \\
\hline 1980 & & 632.483 .750 & 570.859 .597 \\
\hline 1981 & & 805.742 .830 & 519.077 .632 \\
\hline 1982 & & 828.935 .015 & 637.964 .242 \\
\hline 1983 & & 1.476 .532 .472 & 690.424 .544 \\
\hline 1984 & & 1.427 .742 .235 & 583.027 .254 \\
\hline
\end{tabular}


O Estado concede aos usineiros fundos para investimentos e consumo, estes são fundos públicos manipulados a fim de facilitar a dinâmica capitalista na agricultura. Senão vejamos:

o crédito rural é instrumento de política econômica destinado a incentivar a aquisição de produtos industriais por parte da agricultura. Assim, embora pareça apenas um 'privilégio' do setor agrícola, não deixa de ser também um 'crédito ao consumidor', como tantos outros financiamentos existentes no país: o governo paga para que a agricultura ajude a indústria. Mas não a indústria em geral e sim a grande indústria, o grande capital ${ }^{32}$.

Para se ter uma idéia deste subsídio, no período de 1976 a 1980, o Banco do Brasil e o Banco Nacional de Desenvolvimento Econômico, financiavam a implantação, ampliação ou modernização de destilarias de álcool em um prazo máximo de 12 anos, com 3 anos de carência. A taxa de juros era de $17 \%$ ao ano, chegando a financiar até $80 \%$, ou mais em casos especiais, do total do projeto, sendo que as usinas já operantes seriam privilegiadas no recebimento destes recursos. $\mathrm{O}$ plantio da cana-de-açúcar também foi subsidiado, com taxa de juros de $7 \%$ ao ano, prazo máximo de 5 anos, com carência de até 2 anos.

O Estado apóia também as instituições de pesquisa que trabalham com a cultura de cana, como o PLANALSUCAR (Programa Nacional de Melhoramentos da Cana-de-Açúcar), a Copersucar, o Instituto do Açúcar e do Álcool e também pesquisas realizadas em universidades, por exemplo, ESALQ-USP.

Com o suporte financeiro e técnico concedido pelo governo por intermédio do Pró-álcool, as usinas de açúcar e álcool foram fortemente beneficiadas, duplicaram e/ou triplicaram de tamanho, sendo que as áreas dos fornecedores de cana também ampliaram.

Os subsídios governamentais de pesquisa e financiamento concedidos aos produtores de álcool são frutos da arrecadação de impostos dos mais variados setores produtivos do país. Ele será utilizado, no entanto, para beneficiar o empresário particular fortalecendo o seu capital privado.

Além disso, o complexo agroindustrial elabora artifícios para aumentar ainda mais suas facilidades. É o caso de se subdividir em várias propriedades, uma mesma empresa. Assim é que se pode considerar como Usina Nova América todo o complexo agroindustrial, subdividido em várias fazendas: Nova América, Nova Aliança, Tarumã e Dourado.

Todas estas propriedades pertencem diretamente e unicamente à família, mas estão assim organizadas devido às:

Vantagens de um proprietário em manter vários imóveis, ainda que contíguos: a) evita que pela soma das áreas seja classificada como latifúndio por dimensão; b) tem várias unidades distintas para fornecer como garantia hipotecária, o que facilita a burocracia necessária à obtenção de crédito bancário; c) permite 'jogos contábeis' que reduzem impostos devidos; d) no caso específico das Usinas, permite uma operação de arrendamento fictício entre 'duas empresas distintas' de modo a contornar a legislação que fixa uma determinada proporção de quota a ser preenchida pelos fornecedores, etc ${ }^{33}$.

Um dos instrumentos jurídicos criados pelo Estado para legislar na produção sucroalcooleira, como exemplo o Estatuto da Lavoura Canavieira (decreto-lei n. 3.855, de 21/11/1941), é também driblado pelo usineiro para lucrar mais.

Este decreto lei estipula que a usina só pode produzir $40 \%$ da cana que irá transformar em

\footnotetext{
32. GRAZIANO DA SILVA, José. Progresso Técnico e Relações de Trabalho na Agricultura. São Paulo, Hucitec, 1981, p. 100.

33. GRAZIANO DA SILVA, José. Progresso Técnico e Relações de Trabalho na Agricultura. São Paulo, Hucitec, 1981, p. 69.
} 
açúcar e álcool, ficando a quota restante de $60 \%$ distribuída entre fornecedores, que a usina é obrigada a receber pagando um preço que é estipulado pelo Instituto do Açúcar e do Álcool.

Este decreto é uma tentativa de preservar as propriedades vizinhas da usina para que elas não sejam englobadas pela mesma que procura ampliar a sua plantação para atender o ritmo de produção industrial. Entretanto, este decreto não é cumprido, pois as usinas invertem a porcentagem das quotas estabelecidas de produção de cana, chegando, como por exemplo, no caso da usina nova América a produzirem até $68 \%$ da cana utilizada no processo industrial.

No entanto, nem mesmo com essa inversão de cotas poder-se-á realizar um controle, pois a usina poderia arrendar as terras dos fornecedores para a produção de cana para ela própria constando apenas nos autos fiscais, de que foi o fornecedor quem vendeu o produto.

Segundo o gerente da empresa U.N.A. não existe liberdade empresarial no setor sucroalcooleiro, pelo controle governamental exercido:

Dominamos a tecnologia da cana, temos indústrias que operam na fabricação de equipamentos para usina de cana, sabermos o suficiente acerca do cultivo de cana para garantir uma produção econômica... operamos com o preço de venda dominado, preço político, pois ao álcool são atribuídos valores pré-fixados e controlados.

O que se deduz de tudo isso é a existência de um preço oficial estipulado para a compra de matéria-prima, como uma cota de compra da cana do fornecedor pela usina, assim como o préestabelecimento do preço de venda do produto.

As formas empregadas pelos usineiros para se aumentar a produtividade e lucratividade são: maior produção própria em quantidade e melhor qualidade da matéria bruta, para render mais em seu beneficiamento. Tentam reduzir assim ao máximo os custos de sua produção. Isto obrigará a empresa a obter instrumentos tecnológicos de maior precisão no cálculo de seus custos e preços pagos ao fornecedor (pagamento pelo teor de sacarose e não apenas em quantidade e peso). É o aperfeiçoamento de extração de rendimentos no processo de produção do álcool de cana.

Os equipamentos destinados às condições de segurança dos empregados e do meio ambiente serão no máximo os consideráveis indispensáveis pela lei (e na maioria dos casos não serão utilizados). Quanto às reciclagens e a reutilização de determinados dejetos da produção só serão realizados se forem economicamente viáveis,

A racionalidade administrativa e técnica, o ritmo de produção industrial na Usina obrigam o setor agrícola da empresa a se comportar nos mesmos moldes de produção de quantidade, qualidade e ritmo de entrega se matéria bruta (cana) a ser transformada em álcool. Este artigo do jornal da Usina exemplifica bem a situação:

Agrícola Amplia para Abastecer Indústria. "Cerca de 60\% das 12.000 toneladas de cana que a Usina Nova América irá moer na próxima safra, será a quota de fornecimento de cana própria, produzida pela Companhia Agrícola Nova América, cujo gerente de operações Sebastião Carlos Aizzo, explicou que a expansão industrial terá que ser acompanhada de idêntico crescimento agrícola. O gerente comentou também que haverá necessidade de ampliar em $80 \%$ a frota canavieira, da mesma forma como será aumentado o número de cortadores de cana empregados, o mesmo acontecendo com o carregamento da cana cortada.

Isso tudo, segundo disse, está programado e sendo executado porque a expansão industrial exige idêntico comportamento da estrutura agrícola, cujo esquema administrativo também terá que ser adequado.

Constata-se daí que são as exigências do processo de produção industrial que determinam a produção na natureza, tentando-se adaptá-la às mesmas características de controle utilizadas na fábrica (ambiente artificial construído pelo homem). Assim, atende-se às exigências que poderão variar de acordo com a sociedade e as relações sociais de produção nela contidas. 
A produção na U.N.A. ao objetivar o lucro pela redução dos custos, necessita de um aumento na produtividade. Um dos meios para se chegar a este objetivo é pelo melhoramento na qualidade da matéria bruta vegetal tentada através da produção de híbridos.

A produção de híbridos realiza cruzamentos de várias espécies de cana, tentando conseguir uma espécie que seja rica em teor de açúcar e que seja resistente às "pragas".

A engenharia genética aplicada a vegetais tem como objetivo o melhoramento genético para o aumento da produtividade (lucros). No entanto, este melhoramento destrói mecanismos autóctones da planta para a sua proteção, como tecidos resistentes, presença de tanino, sementes muito pequenas, neutralização das enzimas digestivas dos herbívoros, espinhos, produtos de efeito inseticida (rotenona, piretrina, nicotina, estricnina, aletrina, etc.), e isto obrigará o agricultor a adquirir um pacote tecnológico cada vez maior de adubos e defensivos para a proteção da planta "melhorada", aumentando também sua dependência a esses fatores.

A introdução de variedades de cana mais produtivas vai, sem dúvida, ao encontro dos interesses das usinas, dos fornecedores de 'insumos modernos', e até do País como um todo, na medida em que elas permitiram aumentar as exportações a custos. mais baixos ${ }^{34}$.

A U.N.A. implantou um sistema para medir a qualidade da matéria que entra no processo de produção resultando na quantidade final do volume de produção. É o pagamento pelo teor de sacarose.

O sistema implica na retirada de amostras de cana do caminhão carregado; estas amostras serão identificadas, desfibradas e esmagadas e o seu caldo será destinado a uma análise laboratorial que determina o teor de sacarose.

A racionalidade e organização técnica da produção agrícola é auxiliada por terminais de computadores da empresa agilizando o controle e administração da mesma, funcionando comparativamente em igualdade com os setores produtivos considerados mais modernos em ambientes artificiais de trabalho.

A U.N.A. dispõe de sete postos de observação climatológica, que lhe fornece dados objetivos e precisos para elaborar mapas anuais de comportamento climático da micro-área de atuação das estações, contribuindo para orientar as várias operações para o cultivo de cana. Dispõe também de um mapeamento do solo em todo território agricultável da Nova América. O mesmo tem condições de orientar devidamente todas as operações agrícolas da empresa, em conformidade com a natureza do solo, desde o emprego de máquinas e equipamentos, até o uso de fertilizantes e diferentes variedades de cana.

A produtividade agora é uma das palavras chave para o funcionamento da usina. Se no início da formação da empresa faltava em certo método de organização para produção, em 1984 parece que o problema está solucionado. Isso foi resolvido com o mapeamento do solo, o estudo do comportamento climático, a utilização de computadores para se agilizar e centralizar o controle, a leitura do teor de sacarose, o melhoramento da cana por hibridação, e o ritmo e a intensidade da produção agrícola sendo determinada pela produção industrial, estendendo-se até ao controle do desgaste e velocidade da força de trabalho. Este artigo do jornal da Usina nos explicita bem estes pressupostos, quando o gerente de produção:

lembrou que no início da safra, por exemplo, durante a reunião com os fiscais administrativos foi calculado o total de cana cortada por minuto na empresa, e portanto quanto de matéria-prima se deixava de cortar a cada minuto perdido, a mesma forma significativa em ganho para o trabalhador os minutos perdidos durante o dia. Não queremos - continuou - ter supercortadores

${ }^{34}$. SZMRECSANYI, Tamás. Op. cit., p. 413. 
de cana e sim trabalhadores que mantenham a sua produtividade média no mesmo ritmo o ano todo.

Tal como o meio ambiente, os trabalhadores também têm seus limites físicos: um esforço muito intenso dos mesmos pode esgotá-los e reduzir a sua produtividade, quebrando o ritmo médio de fornecimento de matéria bruta, alterando, portanto, a sintonia de produção da usina, que é organizada para trabalhar num movimento constante.

Quanto à produtividade, o fundamental a reter é que o progresso técnico implica um aumento da produtividade do trabalho. E progresso técnico do sistema capitalista significa o progresso das técnicas capitalistas destinadas a aumentar o lucro dos proprietários dos meios de produção ${ }^{35}$.

A racionalidade organizacional não está preocupada com quanto um trabalhador deixa de ganhar por não cortar cana um minuto. Ela está preocupada é que a ausência desta matéria bruta pode prejudicar a sintonia industrial de produção na Usina, ocasionando prejuízos.

A empresa não estará perdendo de uma forma salarial por este minuto perdido, pois o cortador de cana é contratado para ser pago pela quantidade de cana cortada e não pelo tempo de serviço.

Se é muita a preocupação com este minuto "improdutivo" por que a Usina não utiliza cortadeira mecânica? O seu uso foi testado e publicou-se o resultado do teste em seu jornal que é o seguinte:

Trata-se de um equipamento com tecnologia específica que corta a cana inteira, atingindo com suas duas lâminas em ambas extremidades, e deposita-a no solo em sentido longitudinal (contrário ao convencional). A preocupação da empresa, ao desenvolver a experiência decorre da prevista escassez futura de mão-de-obra para o corte de cana, e também da necessidade de dominar esta tecnologia, para empregá-la caso seja necessário; não existe porém nenhuma intenção de substituir o corte manual pelo mecânico, o que só ocorreria na hipótese de falta de mão-de-obra.

Este modelo de máquina também corta cana deitada, e tem como desvantagem, a dificuldade que gera para o carregamento, por depositar a cana em sentido inverso no solo.

Se a empresa tem como objetivo o lucro, que pode ser ampliado através da redução dos custos de produção, por que não utiliza a cortadeira apesar de seu inconveniente para o carregamento? Em alguns casos ela não pode ser usada em terrenos inclinados, no entanto a problemática principal reside no seu custo operacional, tornando vantajoso a utilização da mão-deobra empregada para efetuar tais serviços.

De acordo com o artigo citado, esta máquina só seria empregada em caso de ausência de mão-de-obra. Será que não deve haver nenhuma relação com possíveis futuras greves de trabalhadores neste setor, em que o usineiro utilizaria tais máquinas para substituí-los, servindo como elemento de pressão pela empresa para negociação salarial?

Se a preocupação é com o desemprego, por que a U.N.A. não elimina os caminhões, tratores, carregadeiras e realiza o transporte de cana e preparo da terra com a força humana? Sem dúvida nenhuma ampliar-se-ia em milhares de empregos a serem preenchidos para efetuar os serviços necessários.

$\mathrm{Na}$ realidade, a utilização dos maquinários na produção agrícola vem ao encontro dos interesses e objetivos de ampliação da produção, com baixos custos e com um ritmo mecânico

35. GRAZIANODA SILVA, José \& KAGEYAMA, Ângela P. - produtividade e emprego na agricultura brasileira. In: BELLUZZO, Luiz Gonzaga M. \& COUTINHO, Renata (Org.) - Desenvolvimento Capitalista no Brasil. São Paulo, Brasiliense, 1983, p. 193. 
definido. Os serviços realizados por estes maquinários são os mais diversos: destocamento, gradeamento, subsolagem, aplicação de calcário e adubos, aplicação de biocidas, construção das curvas de nível e carreadores, realização de carregamento, transporte, etc. As suas aquisições são facilitadas por entrarem na parte financiável do projeto Pró-álcool.

Nota-se um considerável aumento no número de tratores de maior potência, comprovada, como se segue, pelos dados do censo agrícola do I.B.G.E. da microrregião da Alta Sorocabana de Assis para os anos de 1975/80.

\begin{tabular}{|c|c|c|c|c|}
\hline Potência & $-10 \mathrm{CV}$ & $\begin{aligned} & 10 \mathrm{à} \\
- & 50 \mathrm{CV}\end{aligned}$ & $\begin{array}{c}50 \text { à } \\
-100 \mathrm{CV}\end{array}$ & $\begin{array}{l}100 \mathrm{CV} \\
\text { e Mais }\end{array}$ \\
\hline $\begin{array}{l}1975 \\
\text { N. }{ }^{\circ} \text { Tratores }\end{array}$ & 38 & 873 & 2.667 & 385 \\
\hline $\begin{array}{l}1980 \\
\text { N. }{ }^{\circ} \text { Tratores }\end{array}$ & 24 & 586 & 3.423 & 777 \\
\hline
\end{tabular}

\section{Terra e fogo da cana}

O solo da U.N.A. está sujeito a compactação devido ao trânsito e a utilização de tratores de grande potência, com implementos pesados utilizados nas operações de cultivo e adubação da cana e também devido ao tráfego constante de caminhões durante operações de carregamento, transporte e aplicação de vinhaça.

Esta compactação é a formação de uma camada dura de terra na superfície do solo, impedindo a infiltração da água (como consequiência não constituindo um lençol freático, elemento hidratador do subsolo), provocando uma erosão laminar que arrasta as partículas do solo para os leitos dos rios; este carregamento ocorre pela inexistência da cobertura vegetal.

Não podemos esquecer também que a cana é uma cultura que propicia tal ocorrência, porque ela fica durante três a quatro anos sem que se realize a operação de revolvimento do solo.

O solo e a sua micro-fauna, quando não são compactados ou arrastados pela erosão são torrados pelo sol, em nosso clima tropical por super-exposição, ou pela queima intencional dos canaviais pela Usina. Essa última prática destrói também as hoje raras árvores que se encontram no meio, ou nas margens do canavial, contribuindo para diminuir a quantidade de oxigênio em nossa atmosfera e aumentar o gás carbônico, monóxido de carbono e calor na biosfera.

O método é aplicado em grandes áreas de até dez mil alqueires, colocando em estado de alerta as cidades vizinhas; ele se realiza devido a interesses de que haja maior rendimento da produção na operação de corte da cana, realizada manualmente pelo bóia-fria que recebe por produtividade.

Se o objetivo da colheita de cana é somente o aproveitamento do colmo, onde concentra-se a maior porcentagem de sacarose, então a folhagem da cana (áspera e cortante) prejudica o trabalho de corte realizado pelo bóia-fria (que deveria trabalhar com roupas adequadas, luvas, enfim, com todo o equipamento necessário) já que ele recebe por produtividade. Esta folhagem, por não ser 
retirada, provoca também o embuchamento e paralização das moendas.

Se por outro lado, se corta a cana com o objetivo de produzir energia (álcool), por que aproveitar somente o colmo para a produção da mesma, queimando a palha, desperdiçando o seu poder calorífico e energético?

Um sério estudo técnico realizado sobre o assunto descreve e calcula quantitativamente o poder calorífico gerador de energia da palha da cana, comparando-o, inclusive, com outras formas de energia:

Waldemar Saffioti em seu artigo: "O desperdício de energia na queima dos canaviais"36, realizou um estudo de amostragem com uma tonelada de cana não queimada, separando o colmo das folhas e ponteiros e através dessa separação constatou a presença de $8 \%$ de palha seca em relação à cana cortada e limpa.

Para uma comparação dos prejuízos provocados pela queima de palha, o pesquisador utilizou dados da produção de cana-de-açúcar do Brasil de 1985, em que a safra atingiu a ordem de 250 milhões de toneladas, portanto queimou-se 20 milhões de toneladas de palha seca, liberando no ar 8,8 milhões de toneladas de carbono sob a forma de gás carbônico, monóxido de carbono e carvão.

Destruiu-se $7.10^{36}$ moléculas de glicose que constituem a cadeia carbônica da celulose; esta perda de energia corresponde comparativamente a 15,5 bilhões de litros de etanol, portanto superior a energia produzida pelo álcool fabricado no Brasil em 1985.

Quanto à energia nuclear a ser produzida em Angra I, II, III e Iguape I avaliada em 4,4 milhões de kilowatts, esta significa apenas a metade da energia desperdiçada na queima dos canaviais.

Ainda comparando com o gás metano que pode ser gerado por biodigestão, este corresponde à metade do álcool de cana produzido em 1984 no Brasil, além do resíduo de cerca de 17 milhões de toneladas, rico em matéria orgânica, a ser utilizado como alimento para gado ou fertilizante no cultivo agrícola.

Além dessa constatação de desperdício de energia, e aumento de poluição gerada pela queima da palha da cana, existem outros desperdícios tão importantes, que são o da prática da monocultura extensiva aos limites da propriedade fundiária, a queima de microorganismos do solo, a queima de oxigênio e contribuindo para ampliar o efeito estufa pela liberação de energia.

\section{O privilégio da monocultura e suas pragas}

A agroindústria ocupa áreas agrícolas e matas naturais buscando espaço na necessidade de produzir matéria-prima para o fabrico do álcool e açúcar para venda no mercado.

Simplifica-se dessa forma, todo o ecossistema, produzindo um desequilíbrio intenso da homeostase e favorecendo o surgimento de pragas, assim como a degeneração do solo.

A monocultura de cana representa uma ameaça na ocupação de terras férteis que eram usadas, ou que poderiam ser usadas, para o plantio de alimentos.

\footnotetext{
${ }^{36}$ SAFFIOTI, Waldemar. O desperdício de energia na queima dos canaviais. Revista Pau Brasil, São Paulo, D.A.E.E., 9, 40-32, Nov/Dez, 1985, p.41.
} 
Esta voracidade de terras por parte da agroindústria infligida pelo ritmo de produção é um reflexo do mercado concorrente capitalista que irá impor a sua racionalidade técnica no processo de produção, impedido pela forma como se estruturam as grandes destilarias (empresas), de se realizar a rotação de culturas, ou o cultivo intercalado, por ausência de área.

Por não haver uma rotação de cultura, no caso uma tentativa de controle por homeostase do ecossistema, verifica-se o surgimento de pragas como: carvão de cana, raquitismo de soqueira, etc.

Esta última para ser solucionada recebe um tratamento de aquecimento das gemas a uma temperatura de $50^{\circ}$ graus, sendo depois mergulhadas em uma solução de fungicida, para serem replantadas no campo em três estágios onde sofrem irrigação.

Os perigos da prática da monocultura são abordados exemplarmente por Jean Dorst:

A monocultura deve ser considerada, na maioria dos casos, como uma das calamidades da agricultura moderna, quando encarada no seu contexto econômico e político. Não se pode, em um plano estritamente biológico, garantir a perenidade do rendimento cultivando apenas uma planta mesmo que se proteja eficazmente o solo, restituindo-lhe os restos da cultura (principalmente fonte de conservação do teor de matéria orgânica) e os elementos que dela foram retirados (distribuindo adubos adequados). É muito raro que isto seja possível e, desse modo, tal prática de cultivo empobrece o solo, fazendo incidir toda a pressão da cultura sobre determinados elementos minerais e orgânicos ${ }^{37}$.

E continua ressaltando as conseqüências dessa simplificação, referindo-se:

Ao fato de o rendimento global de um meio artificial ser nitidamente inferior, comparativamente ao dos meios naturais; no caso de culturas, o desperdício de energia vindo do sol é considerável.

Em vez de explorar as inúmeras possibilidades do meio, deforma-o.

E evidente que uma planta não pode nunca substituir todas as que vivem em estado natural no mesmo local, e o número de plantas cultivadas é incrivelmente pouco elevado relativamente às que constituem o mundo vegetal ${ }^{38}$.

Esta opção pela monocultura, nunca é demasiado enfatizar, é resultado de uma estrutura sócio-econômica, em que se produz para mercado objetivando lucro, segundo cálculos que não levam em conta o desperdício energético, a degradação da limitada natureza, a apropriação centralizada da terra, poder e riqueza, provocando concomitantemente a degradação da força natural e do homem pelo seu passado, seu presente e suas perspectivas de condições de vida.

A cana-de-açúcar é uma planta que pode conviver com outras culturas, mas o seu cultivo sob a forma de monocultura é resultado dos fatores sócio-econômicos da estrutura concentrada da propriedade fundiária.

Entende-se a razão da prática da monocultura enquanto resultado de interesses econômicos-políticos nas mãos dos empresários capitalistas centralizando poder e produção e executando a lógica do capital. Esta lógica funciona da seguinte forma, segundo Engels; "A ciência social da burguesia, a economia política clássica, ocupa-se apenas com os efeitos sociais imediatos a serem obtidos através das atividades humanas dirigidas no sentido da produção e do intercâmbio...

Daí a razão porque os capitalistas, cada um por seu lado, produzem e trocam tendo apenas em vista o lucro imediato e, assim sendo, só podem colocar em primeiro lugar os resultados mais próximos e diretos. Considerando que qualquer industrial

${ }^{37}$. DORST, Jean. Antes que a natureza morra por uma ecologia política. Trad. Rita Buongermino. São Paulo, Ed. Edgard Bucher, 1973, p. 171/172.

38.lbid., p. 338/339. 
ou comerciante apenas se preocupa em vender, com um pouquinho de lucro, embora a mercadoria fabricada ou comprada, está claro que fica satisfeito e não mais se interessa pelo que pode acontecer com a mercadoria e com o seu comprador. $\mathrm{O}$ mesmo (sucede) com as conseqüências naturais dessas mesmas atividades ${ }^{39}$.

Além das já citadas práticas que prejudicam o meio ambiente, ainda fazem parte dessas conseqüências naturais a infestação de pragas que se expressa usualmente com o seguinte significado:

O termo praga aplica-se a animais que são capazes de reduzir a quantidade ou a qualidade de alimentos, rações, forragens, fibras, flores ou madeiras durante a produção, colheita, processamento, armazenagem, transporte ou uso, que podem transmitir doenças ao homem, aos animais domésticos e as plantas cultivadas, que injuriam ou perturbam o homem ou seus animais; que estragam plantas ornamentais, gramados ou. essências florestais; ou que danificam propriedades ou objetos de uso pessoal $^{40}$.

Esta definição generalizadora empregada não leva em conta especificidades que podem ocorrer em determinadas circunstâncias. Por isso ela não é tão esclarecedora e pode levar a sérios enganos. Explicitando:

Os pombos podem ser pragas num milharal, caso seu proprietário tenha como objetivo apenas vender o milho, mas, e se estiver criando pombos também?

Os homens e animais domésticos podem me transmitir doenças. Eles são pragas? A prática exercida pelo homem sobre o meio ambiente pode se revestir e agir com múltiplas finalidades tentando aproveitar respeitar e dar continuidade ao equilíbrio homeostático. No entanto a ratio capitalista utilizada na agricultura por produzir o direcionamento, padronização, unificação das espécies, objetivando produtividade e lucro, denomina selvagens e inúteis às espécies que não foram submetidas ao totem mercadoria com finalidades de mercado pelo empresário.

O capitalismo pode transformar tudo em mercadoria para a sua exploração, desde fulgurantes corpos celestes (veja o cometa Halley e a venda de sua marca) até mesmo a apropriação do Universo, que se deu pelo decreto legislativo n..$^{\circ} 41$ de 2 de outubro de 1968, que aprova o "Tratado sobre princípios reguladores das atividades dos Estados na exploração e uso do Espaço Cósmico, inclusive a Lua e demais corpos celestes", adotado pela Assembléia Geral das Nações Unidas em 19 de dezembro de 1966. Haja pretensão humana!

Enfim, as pragas veiculadoras do desequilíbrio homeostático em sua maioria são decorrentes da ação do homem sobre o meio ambiente, ao estabelecer a agricultura sob a forma de monocultura, utilizando biocidas ${ }^{41}$, introduzindo espécies exógenas em ambientes que não se encontram aptos a receber a espécie alienígena. Afeta-se assim a relação de equilíbrio e suporte de vida da região, por expandir-se numa taxa exponencial, devido a intenso desequilíbrio homeostático, que suprimiria o excesso dessa nova espécie.

As "pragas" podem surgir também das alterações climáticas provocadas ou não, favorecendo determinadas espécies por várias circunstâncias como produção, alimento, competição, predação, dispersão.

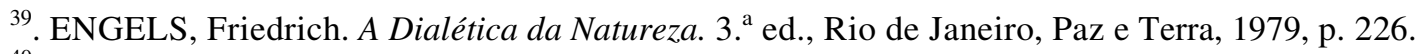

40. PASCHOAL, Adilson D. - Pragas, Praguicidas - A Crise Ambiental, Rio de Janeiro, Fundação Getúlio Vargas, 1979 , p. 15.

${ }^{41}$ Biocidas - Esta denominação é mais esclarecedora do que defensivos, porque expressa que matam também outras espécies (plantas, animais) além das denominadas "pragas", só que tal denominação é prejudicial para venda do produto no mercado por desmascarar a sua ação dizimadora.
} 
A U.N.A., por praticar monocultura simplifica o meio ambiente, provocando o descontrole do ecossistema e o surgimento de "pragas". Para eliminá-las temporariamente (devido ao ressurgimento) a Usina utiliza biocidas, que matam também outros seres vivos.

O biocida mais utilizado na cultura de cana na usina Nova América tem sido o heptacloro e o aldrin, para tentar resolver problemas que foram gerados por ausência de rotação ou intercalação de culturas; planta-se cana há trinta, quarenta anos na mesma área.

O aldrin e o heptac1oro são compostos do grupo de inseticidas organoc1orados. Persistem no solo até mais de trinta anos após a sua aplicação. São lipossolúveis, depositando-se cumulativamente na gordura animal e humana com efeito cancerígeno. Eles penetram no organismo absorvidos pelas vias respiratória, dérmica e oral, atingindo o sistema nervoso central e periférico, provocando lesões e diversos efeitos negativos na saúde dos indivíduos.

O aldrin teve seu uso e comercialização proibidos na comunidade européia desde 1981, exceto em casos especiais no tratamento do solo utilizado para plantas ornamentais. Na União Soviética, Turquia e Israel sua proibição se estendeu até à produção.

O heptacloro de uso restrito no Canadá, Dinamarca e Estados Unidos, teve seu uso e comercialização proibidos na Suécia; República Federal da Alemanha, Nova Zelândia, Turquia e restante comunidade européia.

No Brasil, o seu uso, comercialização e distribuição estão proibidos pela portaria n. ${ }^{0} 329$, de 2 de setembro de 1985 do Ministro de Estado da Agricultura, constituindo exceção à regra nos seguintes casos previstos no parágrafo único do artigo primeiro:

a) $\mathrm{O}$ uso de iscas formicidas à base de Aldrin e Dodecacloro.

b) $\mathrm{O}$ uso de cupinicidas à base de Aldrin para emprego em florestamento e reflorestamento.

c) O uso de referidos produtos quando aplicados pelos órgãos públicos competentes, em campanhas de saúde pública de combate a vetores de agentes etiológicos de moléstias.

d) O uso emergencial na agricultura, a critério da Secretaria Nacional de Defesa Agropecuária - SNAD - do Ministério da Agricultura ${ }^{42}$.

Para controlar o surgimento de "pragas", a usina Nova América utiliza intensamente biocidas em sua monocultura de cana-de-açúcar, acondicionando-os em reservatórios de 8 mil litros.

Este produto é pulverizado pelos trabalhadores nas lavouras sem a mínima preocupação na utilização de equipamentos de proteção, levando a empresa. a ampliar o seu ambulatório para atender casos de intoxicação por via respiratória, resultante da pulverização.

Os efeitos dos biocidas, não se restringem somente à vida humana, mas a todas as espécies desse ecossistema, seja pelos seus efeitos cumulativos e degenerativos, seja pela dizimação rápida da flora e fauna atingidas.

A própria usina realiza uma campanha de captura às cobras encontradas, com uma espécie de colaboração da empresa ao Butantã, que necessita desses répteis para a extração do soro antiofídico, que está se tornando cada vez mais raro, devido ao uso excessivo de biocidas nas lavouras, que provocam o extermínio das cobras.

A empresa procura capturar as cobras vivas para a fabricação do soro, comumente utilizado para salvar pessoas, mas ao mesmo tempo por utilizar biocidas contribui para a dizimação da

42. Secretaria de Agricultura e Abastecimento do Estado de São Paulo, Campinas; 1986, Impresso-especial CATI, 1986, p. 60, anexo 1. 
espécie. Isto denota uma preocupação para com o réptil não enquanto ser vivo, mas por só ser útil no momento em que possa fornecer um antídoto ao humano infectado por um veneno mortal. Qual é o antídoto para o homem, quando se percebe que o veneno mortal da destruição da natureza o modelo de sociedade industrial adotado é fruto de suas concepções antropocêntricas?

Ainda em relação à cobra, entendendo-a como um animal pertencente ao ecossistema cumpre o seu papel na cadeia ecológica ao ser predadora de determinados animais (anfíbios, mamíferos, aves e peixes) controlando naturalmente a expansão demográfica destes, ao mesmo tempo sendo controlada por ser presa de determinados animais (aves de rapina).

Além disso, ao serem carregados pelas chuvas para os rios, esses biocidas matam a sua flora e fauna que é predadora de alguns insetos, provocando mais desequilíbrio ecológico.

\section{Encher o tanque, esvaziar a terra - A Questão Hídrica}

Um dos componentes principais do processo de produção da agroindústria sucro-alcooleira, é a água. Ela é usada em vários momentos e setores da produção (lavagem da cana, resfriamento das máquinas, vapor das caldeiras, serviços de saneamento). Com uma utilização mais intensa deste líquido pela expansão patrocinada pelo Pró-álcool, a usina começará a dedicar uma atenção toda especial, no sentido de racionalizar a sua utilização, visando um reaproveitamento.

O jornal da empresa em um artigo divulga esta preocupação:

Os três milhões e quinhentos mil litros de água por hora necessários à lavagem de cana na Usina Nova América retomam por gravidade depois de utilizados até um grande reservatório construído em alvenaria onde será realizado tratamento para reutilização. Sofre apenas um adicionamento de 50 metros cúbicos, que é igual a 50 mil litros de água limpa por hora, sendo que a mesma quantidade da reposição é retirada do tanque e lançada numa pequena área de sacrifício, mantida exclusivamente para este fim.

Em 72 horas, ou três dias, a quantidade total de água utilizada na lavagem da cana em uma hora (3.600.000 litros) é lançada inteiramente na citada área de sacrifício. Será que este espaço salinizado, e por isto estéril, é pequeno como diz o artigo, já que suporta a água da lavagem da safra inteira e das outras antecedentes e posteriores? Para onde vai a água armazenada no tanque quando termina a safra? Porque a preocupação com a reutilização deste líquido gratuito e abundante é preocupação ambiental? Ou não existe tanta água disponível para a utilização da Usina? São questões que podem ser colocadas face a esses dados.

Em matéria posterior a esta, o mesmo jornal divulga que foi ampliado o sistema de lavagem de cana, de 3.600.000 litros para 4.500.000 litros por hora, expressando o aumento de quantidade de resíduos poluidores que serão jogados na área de sacrifício, conseqüentemente aumentando-a também.

Quanto a água utilizada em outros setores da produção, ela também passa por um processo de tratamento para que voltando ao lago de onde foi retirada, possa conservar a flora e fauna aquática, isto segundo artigo do jornal da Usina:

Toda água servida no complexo industrial de agora em diante sofrerá um tratamento de oxigenação e resfriamento antes de ser lançada de volta ao lago, iniciativa que visa garantir a conservação da flora e fauna aquática.

Constata-se aparentemente até agora que essa preocupação expressa da empresa, em não 
esbanjar o precioso líquido na lavagem de cana e mesmo em tratá-lo para que volte purificado ao lago, é uma preocupação ecológica singular e suspeita, comparando-se este elemento à degradação de outros - flora e fauna silvestres ou à extenuação do solo pela monocultura.

Evidencia-se que os interesses são outros, pois a Usina só km cuidados com este elemento, por constatar que a sua oferta não é ilimitada para suprir as necessidades da voracidade do processo industrial capitalista.

A atenção da Usina em revestir os seus problemas de produção, por extenuação dos recursos naturais ou aproveitamento dos resíduos (vinhaça, torta, restilo, bagaço) com um discurso ecológico, é significativo no intuito de espelhar esta face da Medusa, mas ao visualizá-la diretamente sem a utilização do espelho, petrifica-se por desvendar seus interesses econômicos, o objetivo específico não refletido.

Ainda sobre o problema da água, o órgão de divulgação oficial da usina realiza uma campanha de economia do líquido, junto aos funcionários da empresa e os moradores das colônias, para evitar a falta do líquido.

Percebe-se que a economia é a palavra de ordem para os trabalhadores e colonos, tudo isso para não faltar água, utilizada em grandes quantidades no processo de produção. Só no sistema de lavagem, como exemplo, são utilizados 4.500.000 litros por hora.

Quanto ao tratamento dedicado a água utilizada no processo industrial, esta é decorrência da necessidade de uma melhor qualidade deste líquido para sua reutilização na refrigeração de máquinas.

O ritmo de produção industrial utiliza água em uma velocidade e quantidade maior do que a capacidade de reposição das represas de captação da região, sendo· que em fins de safra elas estão totalmente exauridas.

A Usina justifica investimentos nestes setores da água, vinhaça, bagaço, torta, restilo como se a finalidade fosse fundamentalmente a preocupação com o meio ambiente.

Sem se adotar uma posição exclusivamente maniqueísta, por desvendar que a primeira e principal preocupação da empresa é com a continuidade de seu funcionamento, para ampliar o máximo possível de seu lucro, pode-se perguntar qual flora e fauna local ela quer conservar, e como?

Sabe-se que elas só podem ter condições de sobreviver nas matas naturais que ocupam 0,74\% da área total da Usina, ou na mata ciliar dos riachos e- represas que foram desmatadas para o plantio da cana. Acrescenta-se, ainda, que os animais e vegetais que tentam sobreviver no interior das plantações são mortos nas queimadas ou pelos agrotóxicos, estendendo os seus efeitos poluidores até os cursos d'água. A agroindústria Nova América, por ser e funcionar sob a forma capitalista de produção, preocupa-se principalmente com o seu lucro. Quando adota técnicas de proteção ao meio ambiente é para solucionar os seus problemas imediatos no ciclo da produção, relegando' a último lugar a solução para as conseqüências danosas que ela efetua sobre a natureza.

\section{Poluição e Preservação Ambiental}

Segundo o relatório GURMA da Gerência Unidade Regional de Marília da Companhia de Tecnologia e Saneamento Ambiental CETESB, a U.N.A. figura como a primeira em potencial poluidor das principais usinas da $11 .^{\mathrm{a}}$ Região Administrativa. 
Esta usina também aparece no relatório elaborado pela CA TI - Divisão Regional de Marília, com a seguinte área total de matas naturais: 33,88 Ha, sendo que a área total da empresa em 1984, era de 25.137 Ha.

Desta forma não respeita a lei No 4.771 de 15 de setembro de 1965 que institui o novo código florestal, no seu artigo 16, alínea "a" que exprime o seguinte:

Art. 16 - As florestas de domínio privado, não sujeitas ao regime de utilização limitada e ressalvadas as de preservação permanente, prevista nos artigos $2 .^{\circ}$ e $3 .^{\circ}$ desta lei, são susceptíveis de exploração, obedecidas as seguintes restrições:

a) Nas regiões Leste Meridional, Sul e Centro-Oeste, está na parte sul, as derrubadas de florestas nativas, primitivas ou regeneradas, só serão permitidas desde que seja, em qualquer caso, respeitado o limite mínimo de $20 \%$ da área de cada propriedade com cobertura arbórea, a critério da autoridade competente ${ }^{43}$.

A Usina Nova América não respeita também o artigo 2. ${ }^{0}$ alíneas a e b que consideram áreas de preservação permanentes a vegetação natural situada ao longo dos rios, preservando uma faixa mínima de cinco metros para rios de menos de dez metros de largura e ao redor de lagoas, lagos ou reservatórios d'água naturais ou artificiais. Se a empresa respeitasse estas normas e porcentagens, instituídas no código florestal, sua área de mata natural deveria ser de 5.027,40 Ha. Desta forma, está defasada em 4.993,52 Ha.

Apesar de toda essa ausência de vida florestal para o equilíbrio do meio ambiente, a polícia florestal cumprimenta a empresa por não poluir, em notícia veiculada no jornal da Usina, que mostra em foto o diploma de menção honrosa que a Nova América recebeu da polícia florestal.

A Usina divulgava exemplarmente a sua preocupação com o meio ambiente através de artigos publicados em seu jornal:

\section{Não matem os animais}

Ninguém deve matar os cachorros do mato que são encontrados na cana, nem os gatos ou raposas. Isto porque estes animais estão acabando e eles não podem acabar porque fazem parte da natureza. Por exemplo, são eles que comem as pombinhas que tem no meio da cana, e não deixam aumentar muito essas aves, porque os gatos, cachorros e raposas do mato também consomem os ovos das pombas.

Como se vê este artigo é altamente contraditório, pois se, não se deve matar os animais porque eles integram a natureza, então qual o interesse em matar as pombas se elas também integram a natureza?

Todas são importantes, pois participam e realizam a sinfonia da vida. Com as suas ausências surgem os desequilíbrios que tentarão ser consertados por doses maciças de agrotóxicos, prejudicando, no final do ciclo, também o homem. Além do que há uma questão política, porque vizinha à cultura de cana na região (que se torna, por falta de estrutura ecológica, abrigo para as pombas), tem-se a rotação anual da cultura de grãos (soja e trigo) que se transformam em alimentos para as aves, criando problemas, portanto, de relacionamento sócio-político entre os usineiros e os plantadores destas culturas.

A Usina, para proteger o solo do cultivo intensivo e extensivo da monocultura da cana, tem que aplicar normalmente adubação química e orgânica para repor os nutrientes utilizados, pois ele caminha para a sua exaustão. Desta forma ela será obrigada a adotar práticas de manejo do solo na quantidade mínima suficiente para que possa manter sua produção.

\footnotetext{
43. Secretaria de Estado dos Negócios da Agricultura - Serviço Florestal, Legislação Florestal, São Paulo, s/d, p. 4.
} 
Uma dessas práticas de manejo é a adubação verde, contribuindo para aumentar a matéria orgânica e evitar a erosão. O plantio direto é também uma das práticas utilizadas para a conservação do solo, devido à existência de áreas impróprias à intensa sucessão de operações de aração, gradeamento e subsolagem, podendo tomá-las totalmente erodidas e estéreis.

A Usina também utiliza amplamente como fertilizante a vinhaça ou vinhoto, que é o resíduo do processo de extração do álcool da cana-de-açúcar e que era desperdiçado por ser lançado nos cursos d'água ou áreas de sacrifício sendo que estes ficavam poluídos e estéreis pela acidez contida na vinhaça.

A matéria orgânica vinhaça é produzida na proporção de 15 (quinze) litros para 1 (um) de álcool. A partir da safra de 1982 a Usina iniciou um processo de irrigação das lavouras de cana por canais, sistemas de bombas de aspersão e caminhões, eliminando o problema de sua descarga em rios e zonas de sacrifício e ao mesmo tempo substituindo parte da adubação química onerosa.

A produção de vinhaça em 1984 foi de 1 bilhão, 612 milhões e 500 mil litros; resta-nos saber se, no decorrer do tempo e intensiva aplicação do produto não irá tomar o solo ácido?

Como complementar à aplicação nas áreas irrigadas com vinhaça, a uréia foi adotada por demonstrar eficiência. A comparação na redução de custos da substituição da adubação química pela vinhaça, equivale em porcentagens a $75 \%$, sem contar o enriquecimento da micro fauna.

O bagaço, um dos resíduos de produção da usina, é aplicado e testado em diferentes setores como alimento de gado, fertilizante ou gerador de energia.

Como alimento de gado ele deve ser tratado anteriormente com hidróxido de sódio acrescido de melaço. Depois de ser metabolizado pelo organismo dos bovinos ele pode ser utilizado como fertilizante orgânico em condições de substituir os químicos. Ressalve-se que outros alimentos dos bovinos depois de metabolizados por seu organismo também se transformam em fertilizantes.

O bagaço é utilizado "in natura" como complementar a adubação química, para diminuir os seus custos, ampliando a margem de lucro. O bagaço pode ser também aproveitado para gerar energia com a sua combustão nas caldeiras da refinaria de açúcar.

A Usina ainda aproveita para alimento de gado $1 \%$ do restilo (um dos principais resíduos de sua produção industrial), que contém levedura (células vivas) com $32 \%$ de proteínas na complementação da ração animal.

A "torta", matéria orgânica produzida em uma média diária de 200 toneladas, é totalmente distribuída nos canaviais. Ela faz parte como o bagaço, o restilo e a vinhaça, dos dejetos da produção industrial. Os reaproveitamentos destes resíduos têm como objetivo principal aumentar os lucros da empresa, pela redução de custos como aplicação sob a forma de fertilizantes (vinhaça, bagaço, torta), substituindo os adubos químicos, como combustível para as caldeiras sob a forma de bagaço, ou alimento para o gado (bagaço tratado, levedura), mas que acabam, ainda que levemente, produzindo aspectos positivos no meio ambiente, normalmente tão agredido pela dita empresa. 